\title{
CORRELATING HEALTH EXAMINATIONS WITH CLASS TEACHING
}

\author{
Earle E. Kleinschmidt, M.D. \\ Instructor in Hygiene and Public Health, University of Michigan, Aın Arbor, Mich.
}

For sime time the educational content latent in the health examination program has engaged the attention of educators and physicians alike. Certain it is that schools have only begun to use this procedure as a means for properly motivating children toward wholesome living habits. In far too many school systems the examination is still regarded as an extrinsic activity of the school despite its many educational values.

Granting the necessity of a health examination program in a school system, can educators afford to turn aside the many educational opportunities afforded by such examinations and continue to provide children with this experience without educating them as to the "why" of it? The answer is unquestionably in the negative.

Making the health examination an educational experience calls for the closest cooperation between health workers and the classroom teacher. The teacher of today, however, faces a task for which she has had little, if any, preparation in most instances. Despite this all too prevalent situation, one must face the paradox of a program the success of which is directly dependent on the health awareness of this teacher. Adjustment to this situation is an important problem for health councils and normal schools to solve. All too often the perplexed teacher is confronted with a new course of study for which neither she nor her supervisors have adequate background to organize properly or to integrate into an already overcrowded curriculum. The fault is due neither to the teacher nor to the system. Confronting the school is a dynamic movement for human betterment which is as yet in its infancy, and to no one is it especially clear as to how this urge should fit into the social scheme. Suffice it to say that the health worker, whether physician or nurse, has much information of value in orienting the teacher in the newer problems of health education.

The philosophy underlying a health program determines in a large measure its functional activities. The Ann Arbor public schools have set up a health creed on which it is hoped that a health program can be built. This is described by Otto W. Haisley in an article, "Adjusting Health Education to the Newer Trends in Educational Philosophy," which appeared in Health and.Physical Education, October, 1932.

It is not my purpose to discuss the merits or the construction of a unit in health education. It is important, however, to emphasize the fact that the development of a teaching unit about the health ex- 
amination offers a situation of many possibilities in the furtherance of the school health program. I have discussed this in greater detail in "Health Examinations in Schools," an article which appeared in the School Physicians' Bulletin, April, 1933. The health examination lends itself well to this form of teaching. In such a unit, pupil purposing, planning, executing and appraising are entirely possible as contrasted with the former passive procedure. Interestingly enough the health examination unit becomes a keystone around which objectives for classroom instruction can be further developed. Every teacher who is alert to the possibilities and who plans as the unit progresses is doubtless aware of this.

The teacher may choose whatever approach she thinks best, depending on her own situation and the opportunities she is able to command. She may well resort to the regular activities of the school medical staff. Some of the children have undergone life insurance examinations. Others may be aware of the examinations given athletes. Still others may have heard of the intensive examinations given railroad engineers, airplane pilots, explorers and automobile operators. The story of Ellis Island is always a source of interest. Perhaps best of all the teacher may tell of her last periodic health examination. During this period of study the teacher may suggest that the school physician should demonstrate and explain an examination.

Because of its appeal to social approval this approach has much that is commendable in motivating children to want to have an examination. Heretofore a visit to a physician has been associated with fear, pain and a number of technical happenings for which no explanation was given. To be sure, the child has been curious. Only circumstance has prevented him from learning. The school health examination is one pregnant with many possibilities with which the teacher guides and stimulates pupil activity.

Growing out of the health examination given a class are both individual and group health appraisals. The physician in his examination gathers direct information of the physical, emotional and social needs of the children. These data must be presented to the teacher in practical form for use as a basis for further instruction; for example. the finding of a number of underweight children might lead to the study of an adequate diet. One may say then that the needs of the children, once discovered, form the basis for formulating objectives for further classroom activity. -Hygeia, January, 1934 .

"Approximately 5,00o more sight-saving classes are needed in the United States to provide educational advantages for children with impaired vision, for it is estimated that 47,000 pupils in the entire school population are suffering from defective vision." 